\title{
Time to improve awareness of restless legs syndrome
}

\author{
Jan Ulfberg \\ Department of Medicine, Uppsala University, Uppsala, Sweden
}

\author{
Address for correspondence: \\ Prof. Jan Ulfberg, \\ Department of Medicine, Uppsala \\ University, Uppsala, Sweden. E-mail: \\ jan.ulfberg@Itdalarna.se \\ PMID: *** \\ DOI: $10.4103 / 0028-3886.59462$
}

Restless legs Syndrome (RLS) is a disorder that hardly receives the attention it should deserve. A study conducted in Europe and United States suggests that RLS is greatly under-diagnosed and under-treated. ${ }^{[1]}$ The American patients' organization, Restless Legs Syndrome Foundation has taken account of these observations and often reminds us that RLS is "the most common disorder you have never heard of" (www.rls.org).

In 1945, Karl-Axel Ekbom, a Swedish neurologist published his thesis "Restless legs. A clinical study of a hitherto overlooked disease in the legs" and termed the disorder as RLS. ${ }^{[2]}$ This thesis is considered the most substantial and comprehensive work on RLS. The reported prevalence of RLS in the population of Stockholm was $5.2 \%$ with a slight female predominance. Some of the observations made by Ekbom remain classic till today: "The patients sleep may be disturbed night after night for years." "In its most severe form it causes great suffering." "The disease is so common that every practicing physician meets it." "After one's attention has been drawn to it, it is generally easy to diagnose".

Epidemiological data on RLS are quite variable and probably related to the methodological issues. It is important to define the study population; probably random sampling is the most appropriate method. Faceto-face interviews and examination by trained physicians are the most sensitive and specific ways to acquire the data. Diagnosis of RLS should be by using the "International Restless Legs Syndrome Study Group (IRLSSG)" criteria. ${ }^{[3]}$ In this issue, researchers from Turkey present the data on the prevalence of RLS in one of the regions in Turkey. ${ }^{[4]}$ The methodology of the study is quite comprehensive. The study is a population-based study and by face-to-face interviews. The diagnosis was based on the IRLSSG criteria. The estimated prevalence of RLS of $9.7 \%$ in their population, therefore, seems reliable. However, use of lower age limit as 40 years is a major drawback. ${ }^{[4]}$

In the last decade a large number of epidemiological studies have been conducted on RLS. Majority of the studies were mainly on the Caucasians in Northern Europe and the United States of America. The prevalence of RLS among Caucasians is approximately $5-15 \% .^{[5-7]}$ RLS is more common in women and the age of presentation is between forties and fifties. Till date there have been a few published studies on the prevalence of RLS in Asia, Africa and South-America. RLS rates are until now considered to be low in some Asian populations. ${ }^{[8,9]}$ The prevalence of RLS in two samples in the Singapore-area was only 0.6 and $0.1 \%$, respectively. ${ }^{[9]}$

This study form Turkey emphasizes lack of awareness among patients and also the treating physicians. ${ }^{[4]}$ In the other studies also such lack of knowledge among the patients and also among the healthcare workers has been observed. ${ }^{[1,7]}$ However, it is not clear whether this lack of health-attention seeking behavior on the part of the patient is related to his/her threshold to bear the symptoms of RLS. Earlier RLS was considered a harmless symptom. However, recent studies have clearly defined the neuropathological basis of the symptoms and also evolved effective treatments in RLS. ${ }^{[10]}$ 
Earlier the consequences of RLS on the other aspects of health are not well defined. However, now we know that RLS is a major cause of insomnia and the sleep-related symptoms often brings the patients to medical attention. ${ }^{[1,2,5,6,10]}$ In addition, sleep loss and fragmentation of sleep related to RLS has a major impact on health and daytime functioning. ${ }^{[1,2,5,6,10]}$ The data presented in the article from Turkey is a corroboration of this. Association with other co-morbidities such as coronary artery disease has been documented. ${ }^{[4,5]}$ The finding of bronchial asthma as co-morbidity is a new finding in this study. ${ }^{[4]}$

Thus, as said by Ekbom, a great responsibility lies for the physicians and researchers committed to do research on RLS to educate the health care givers and the public about "this common disease which is seen by every practicing physician, which may cause great suffering and is generally easy to diagnose". ${ }^{[2]}$

\section{References}

1. Hening W, Walters AS, Allen RP, Montplaisir J, Myers A, Ferini-Strambi L. Impact, diagnosis and treatment of restless legs syndrome (RLS) in a primary care population: The REST (RLS epidemiology, symptoms, and treatment) primary care study.
Sleep Med 2004;5:237-46.

2. Ekbom KA. Restless legs. Acta Med Scand 1945;158:1-123.

3. Walters AS; the International Restless Legs Syndrome Study Group. Toward a better definition of the restless legs syndrome. Mov Disord 1995;10:634-642.

4. Erer S, Karli N, Zarifoglu M, Ozcakir A, Yildiz D. The prevalence and clinical features of restless legs syndrome in Orhangazi, Bursa in Turkey: A door to door population study. Neuro India 2009;57:729-33.

5. Ulfberg J, Nyström B, Carter N, Edling C. Prevalence of restless legs syndrome among men aged 18 to 64 years: An association with somatic disease and neuropsychiatric symptoms. Mov Disord 2001;16:1159-63.

6. Bjorvatn B, Leissner L, Ulfberg J, Gyring J, Karlsborg M, Regeur L, et al. Prevalence, severity and risk factors of restless legs syndrome in the general adult population in two Scandinavian countries. Sleep Med 2005;6:307-12.

7. Tison F, Crochard A, Legér D, Bouée S, Lainey E, El Hasnaoui A. Epidemiology of restless legs syndrome in French adults: A nationwide survey, The INSTANT study. Neurology 2005;65:239-46.

8. Sevim S, Dogu O, Camdeviren H, Bugdayci R, Sasmaz T, Kaleagasi H, et al. Unexpectedly low prevalence and unusual characteristics of RLS in Mersin, Turkey. Neurology 2003;61:1562-9.

9. Tan EK, Seah A, See SJ, Lim E, Wong MC, Koh KK. Restless legs syndrome in an Asian population: A study in Singapore. Mov Disord 2001; $16: 577-9$

10. Trenkwalder C, Paulus W, Walters AS. The restless legs syndrome. Lancet Neurol 2005;4:465-75.

Accepted on 23-12-2009

Source of Support: Nil, Conflict of Interest: None declared. 